Article

\title{
Testing of the Survivin Suppressant YM155 in a Large Panel of Drug-Resistant Neuroblastoma Cell Lines
}

\author{
Martin Michaelis ${ }^{1}$, Yvonne Voges ${ }^{2}$, Florian Rothweiler ${ }^{2}$, Fabian Weipert ${ }^{3}$, Amara Zia-Ahmad ${ }^{2}$, \\ Jaroslav Cinatl ${ }^{2}$, Andreas von Deimling ${ }^{4}$, Frank Westermann ${ }^{5}$, Franz Rödel ${ }^{3}$, Mark N. Wass ${ }^{1}$ \\ and Jindrich Cinatl Jr. 2,* \\ 1 Industrial Biotechnology Centre and School of Biosciences, University of Kent, Canterbury CT2 7NJ, UK; \\ M.Michaelis@kent.ac.uk (M.M.); M.N.Wass@kent.ac.uk (M.N.W.) \\ 2 Institut für Medizinische Virologie, Goethe-Universität, 60596 Frankfurt am Main, Germany; \\ yvonnevoges@gmx.de (Y.V.); f.rothweiler@kinderkrebsstiftung-frankfurt.de (F.R.); \\ amara_zia12@yahoo.de (A.Z.-A.); ja.cinatl@kinderkrebsstiftung-frankfurt.de (J.C.) \\ 3 Department of Radiotherapy and Oncology, Goethe-Universität, 60590 Frankfurt am Main, Germany; \\ fabian.weipert@gmail.com (F.W.); Franz.Roedel@kgu.de (F.R.) \\ 4 Department of Neuropathology, Ruprecht-Karls-University Heidelberg and Deutsches \\ Krebsforschungszentrum, 69120 Heidelberg, Germany; andreas.vondeimling@med.uni-heidelberg.de \\ 5 Division Neuroblastoma Genomics, B087, German Cancer Research Center and Hopp Children's Cancer \\ Center at the NCT (KiTZ), 69120 Heidelberg, Germany; f.westermann@dkfz-heidelberg.de \\ * Correspondence: Cinatl@em.uni-frankfurt.de; Tel.: +49-69-6301-6409 (F.L.)
}

Received: 27 January 2020; Accepted: 28 February 2020; Published: 2 March 2020

\begin{abstract}
The survivin suppressant YM155 is a drug candidate for neuroblastoma. Here, we tested YM155 in 101 neuroblastoma cell lines (19 parental cell lines, 82 drug-adapted sublines). Seventy seven (77) cell lines displayed YM155 IC 50 in the range of clinical YM155 concentrations. ABCB1 was an important determinant of YM155 resistance. The activity of the ABCB1 inhibitor zosuquidar ranged from being similar to that of the structurally different $A B C B 1$ inhibitor verapamil to being 65 -fold higher. $A B C B 1$ sequence variations may be responsible for this, suggesting that the design of variant-specific ABCB1 inhibitors may be possible. Further, we showed that ABCC1 confers YM155 resistance. Previously, p53 depletion had resulted in decreased YM155 sensitivity. However, TP53-mutant cells were not generally less sensitive to YM155 than TP53 wild-type cells in this study. Finally, YM155 cross-resistance profiles differed between cells adapted to drugs as similar as cisplatin and carboplatin. In conclusion, the large cell line panel was necessary to reveal an unanticipated complexity of the YM155 response in neuroblastoma cell lines with acquired drug resistance. Novel findings include that ABCC1 mediates YM155 resistance and that YM155 crossresistance profiles differ between cell lines adapted to drugs as similar as cisplatin and carboplatin.
\end{abstract}

Keywords: YM155; survivin; neuroblastoma; drug resistance; ABCB1; ABCC1

\section{Introduction}

The inhibitor of apoptosis protein (IAP) survivin has multifaceted roles in cellular signalling. It is absent from most somatic cells but highly abundant in cancer cells and mediates cancer cell survival and proliferation. Elevated survivin levels have been associated with more aggressive and advanced cancer disease and lower survival rates. Hence, survivin is a potential drug target in cancer entities including neuroblastoma [1-10], the most frequent solid extracranial paediatric cancer. About half of the patients are diagnosed with high-risk disease associated with overall survival rates below $50 \%$ despite myeloablative therapy and differentiation therapy using retinoids. While many neuroblastomas respond initially well to therapy, acquired drug resistance represents a major clinical problem [11,12]. 
YM155 (sepantronium bromide) was introduced as a suppressor of survivin expression that displayed anti-cancer activity in pre-clinical models of different cancer entities including neuroblastoma [6-8,10,13]. However, DNA damage induction and Mcl-1 depletion were later suggested as additional or alternative anti-cancer mechanisms of YM155 [8,14-18]. We recently confirmed that YM155 exerts its anti-neuroblastoma effects predominantly through survivin suppression [10]. YM155-induced survivin suppression proceeded DNA damage formation. Moreover, YM155 mimicked the effects of RNAi-mediated survivin depletion, whereas Mcl-1 depletion did not affect neuroblastoma cell viability [10]. Furthermore, YM155-adapted UKF-NB-3 neuroblastoma cells had developed resistance to RNAi-mediated survivin depletion [10]. We also investigated the effects of YM155 in neuroblastoma cells with acquired resistance to cisplatin, doxorubicin, or vincristine and detected in concert with previous findings reduced SLC35F2 (mediates cellular YM155 uptake) and increased ABCB1 (causes YM155 efflux) expression as drugspecific resistance mechanisms [6,10,19,20]. Our data further demonstrated that RNAi-mediated p53 depletion mediated resistance to YM155 and survivin depletion suggesting loss of p53 function to be a target-specific resistance mechanism that will affect all approaches that target survivin in neuroblastoma [10].

Here, we investigated the effects of YM155 in a larger panel of 101 neuroblastoma cell lines that focused on acquired drug resistance containing 82 drug-adapted neuroblastoma cell lines, which reflected resistance to 15 anti-cancer drugs.

\section{Results}

\subsection{Effects of YM155 on the Viability of Parental Neuroblastoma Cell Lines}

YM155 was initially tested in a panel of 86 neuroblastoma cell lines consisting of 17 parental neuroblastoma cell lines and 69 drug-adapted sub-lines (Table S1). The IC 50 values in the parental cell lines ranged from $0.49 \mathrm{nM}$ (UKF-NB-3) to $248 \mathrm{nM}$ (LAN-6) (Figure 1, Table S1). All parental cell lines despite from LAN-6, NB-S-124 (77 nM), and SK-N-SH (75 nM) had IC50 values in the range of clinical achievable YM155 plasma concentrations (Figure 1A, Table S1) that were reported to reach up to 56 $\mathrm{nM}$ [21-23].

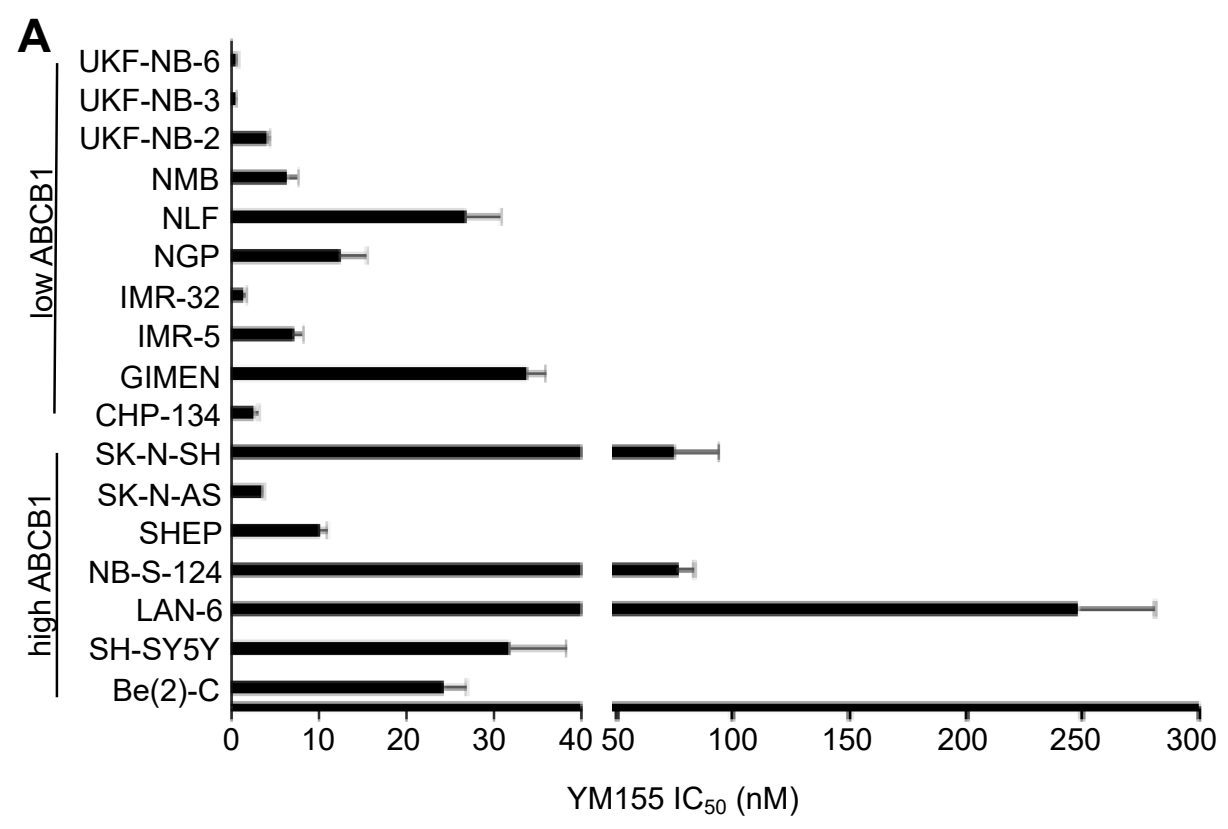




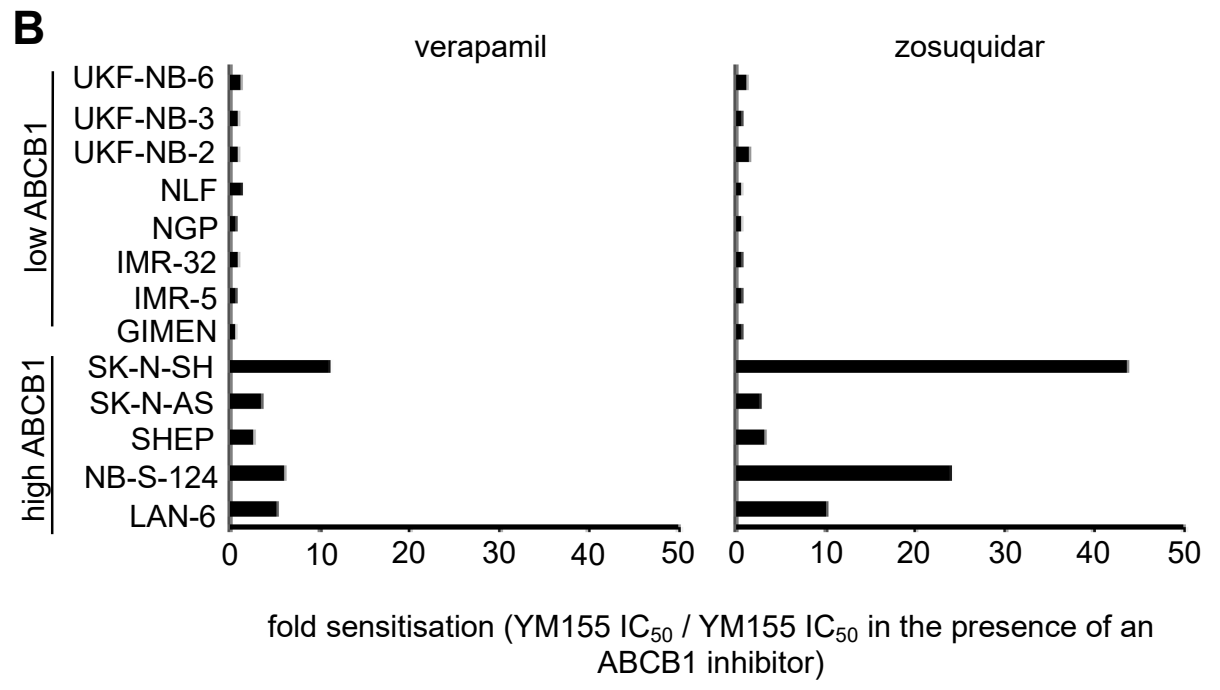

Figure 1. Anti-neuroblastoma effects of YM155 in a panel of 17 neuroblastoma cell lines. (A) YM155 concentrations that reduce the viability of neuroblastoma cell lines by $50 \%$ (IC50, mean \pm S.D., $n=3$ ) as determined by MTT assay after a 5-day treatment period. Numerical values are presented in Table S1. Information on the ABCB1 status of the cell lines is provided in Table S2. (B) Effects of the ABCB1 inhibitors verapamil $(5 \mu \mathrm{M})$ and zosuquidar $(1.25 \mu \mathrm{M})$ on the YM155 IC 50 values in neuroblastoma cell lines characterised by high or low ABCB1 levels displayed as fold change YM155 IC 50 / YM155 IC50 in the presence of $A B C B 1$ inhibitor. Numerical data and the effects of the ABCB1 inhibitors alone on cell viability are presented in Table S6.

\subsection{ABCB1-Expressing Neuroblastoma Cell Lines Display Low Sensitivity to YM155}

In concert with previous studies [6,10], high ABCB1-expressing neuroblastoma cells generally displayed relatively low YM155 sensitivity (Figure 1A). In a subset of these cell lines, only the high ABCB1-expressing cells were (in contrast to low ABCB1-expressing cells) sensitised to YM155 by verapamil and zosuquidar (Figure 1B), two structurally unrelated ABCB1 inhibitors [24].

\subsection{MYCN Status Does Not Influence Neuroblastoma Cell Sensitivity to YM155}

MYCN amplification is a major determinant of poor disease outcome in neuroblastoma [11,12]. The YM155 IC50 ranged from $0.49 \mathrm{nM}$ (UKF-NB-3) to $77 \mathrm{nM}$ (NB-S-124) in MYCN-amplified cells and from $3.55 \mathrm{nM}$ (SK-N-AS) to $248 \mathrm{nM}$ (LAN-6) in not MYCN-amplified cells (Table S4). To exclude the effects of ABCB1, we compared the YM155 IC 50 in cells with known MYCN status in the presence of the $A B C B 1$ inhibitors verapamil and zosuquidar. In the presence of $A B C B 1$ inhibitors, MYCNamplified and non-MYCN-amplified displayed a similar range of YM155 IC50s (Figure 2A, Table S3). SH-EP-MYCN (TET21N) cells express a tetracycline-controllable MYCN transgene. They display low MYCN levels in the presence of tetracycline antibiotics and high MYCN levels in the absence of tetracycline antibiotics [25]. SH-EP-MYCN (TET21N) cells displayed similar YM155 IC50 values in the absence or presence of doxycycline (Figure 2B, Figure S1). 
A
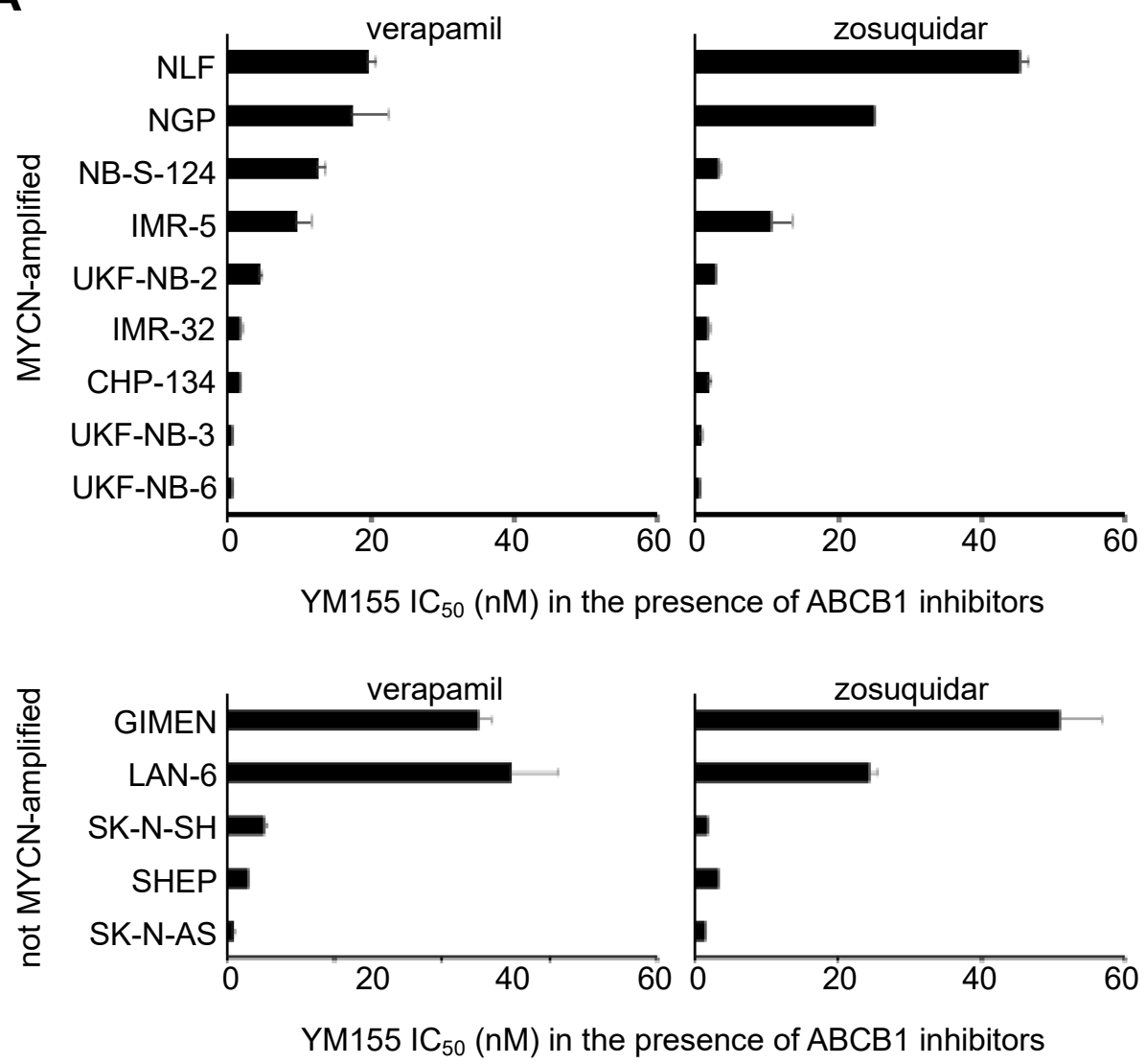

B

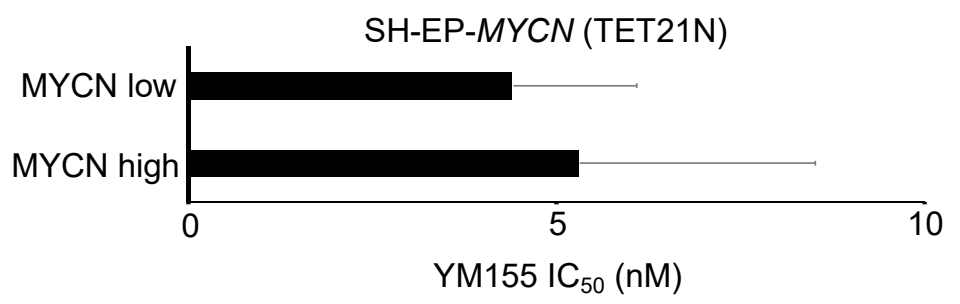

Figure 2. Effects of YM155 on the viability of neuroblastoma cells in dependence on the MYCN status. (A) YM155 concentrations that reduce the viability of neuroblastoma cell lines by $50 \%$ (IC50) were determined by MTT assay after a 5-day treatment period in the presence of the ABCB1 inhibitors verapamil $(5 \mu \mathrm{M})$ or zosuquidar $(1.25 \mu \mathrm{M})$ to avoid interference of ABCB1-mediated effects with MYCN-mediated effects. Numerical data are presented in Table S3. (B) YM155 IC50 values in SH-EPMYCN (TET21N) cells in the absence or presence of doxycycline as determined by MTT assay after a $120 \mathrm{~h}$ of treatment. All values are presented as mean \pm S.D. $(n=3)$.

\subsection{TP53 Status Does Not Predict Neuroblastoma Cell Sensitivity to YM155}

Previously, RNAi-mediated p53 depletion was shown to reduce the YM155 sensitivity of the neuroblastoma cell lines UKF-NB-3 and UKF-NB-6 [10]. However, the p53-null SK-N-AS cells displayed an YM155 IC 50 of $3.55 \mathrm{nM}$ that was further reduced to $1.01 \mathrm{nM}$ and $1.31 \mathrm{nM}$ by verapamil and zosuquidar, respectively (Figure 1, Table S3). Hence, SK-N-AS belongs in the presence of ABCB1 inhibitors to the most YM155-sensitive neuroblastoma cell lines in the panel, despite the lack of functional p53.

To further investigate the relevance of the TP53 status for the neuroblastoma cell sensitivity to YM155, we determined YM155 IC50 values in a panel of 14 nutlin-3-adapted TP53-mutant 
neuroblastoma cell lines [26,27]. Our initial cell line panel included one nutlin-3-adapted neuroblastoma cell line (UKF-NB-3r Nutlin ${ }^{10 \mu \mathrm{M}}$ ) that harbours a G245C loss-of-function TP53 mutation [26] and displayed 2.4-fold reduced YM155 sensitivity relative to the parental UKF-NB-3 cells (Table S1). In addition, we tested YM155 in nutlin-3-resistant, TP53 mutant sub-lines of two clonal p53 wildtype UKF-NB-3 sub-lines (UKF-NB-3clone1, UKF-NB-3clone3) and the TP53 wild-type neuroblastoma cell line UKF-NB-6 (Figure 3, Table S5). Only four out of the 14 nutlin-3-resistant neuroblastoma cell lines displayed a $>2$-fold change in the YM155 IC 50 relative to the respective

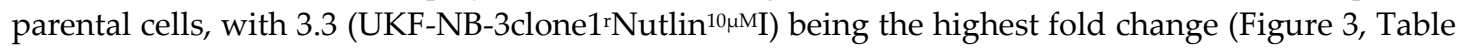
S4). These findings do not suggest the cellular TP53 status to be a good predictor of neuroblastoma cell sensitivity to YM155.



Figure 3. Effects of YM155 on the viability of parental p53 wild-type neuroblastoma cell lines and their p53 mutant nutlin-3-adapted sub-lines. YM155 concentrations that reduce neuroblastoma cell viability by $50 \%\left(\mathrm{IC}_{50}\right.$, mean \pm S.D., $\mathrm{n}=3$ ) as determined by MTT assay after a 5 -day treatment period. Numerical data are presented in Table S4.

\subsection{Effects of YM155 on the Viability of Neuroblastoma Cell Lines with Acquired Drug Resistance}

In a panel of 69 sub-lines of the neuroblastoma cell lines IMR-5, IMR-32, NGP, NLF, SHEP, UKFNB-2, UKF-NB-3, and UKF-NB-6 with acquired resistance to drug classes including platinum drugs, vinca alkaloids, taxanes, alkylating agents, topoisomerase I inhibitors, topoisomerase II inhibitors, and nucleoside analogues (Table S1), resistance was commonly associated with decreased YM155 sensitivity. However, 48 resistant cell lines displayed YM155 IC 50 values in the range of therapeutic plasma levels (up to $56 \mathrm{nM}$ ) (Table S1).

Forty one (41) of the resistant cell lines (60\%) displayed cross-resistance to YM155 (YM155 IC50 resistant sub-line/ YM155 $\mathrm{IC}_{50}$ respective parental cell line $>2$ ). Twelve of these cell lines showed a fold change YM155 IC50 resistant sub-line/ YM155 IC50 respective parental cell line of $>2$ and $<10,18$ $(26 \%)$ cell lines a fold change $>10$ and $<100$, and $11(16 \%)$ cell lines a fold change $>100.20(29 \%)$ resistant cell lines were similarly sensitive to YM155 like the respective parental cell lines (fold change $<2$ and $>0.5)$. Seven $(10 \%)$ resistant cell lines were more sensitive to YM155 than the respective parental cell lines (fold change <0.5) (Table S1). There were cell line-specific differences. For example, eight out of nine (89\%) UKF-NB-3 sub-lines and nine out of 10 (90\%) UKF-NB-6 sub-lines, but only two out of 11 NLF sub-lines (18\%) displayed cross-resistance to YM155 (Table S1).

The YM155 IC 50 values in the drug-resistant cell lines ranged from $0.40 \mathrm{nM}$ (UKF-NB-3rGEMCI ${ }^{10}$ ) to $21,549 \mathrm{nM}$ (IMR-5rDOCE ${ }^{20}$ ) (Table S1). Drug class-specific differences in the YM155 resistance profiles can be observed, but the variation of the results is very large (Figure 4, Table S5). 


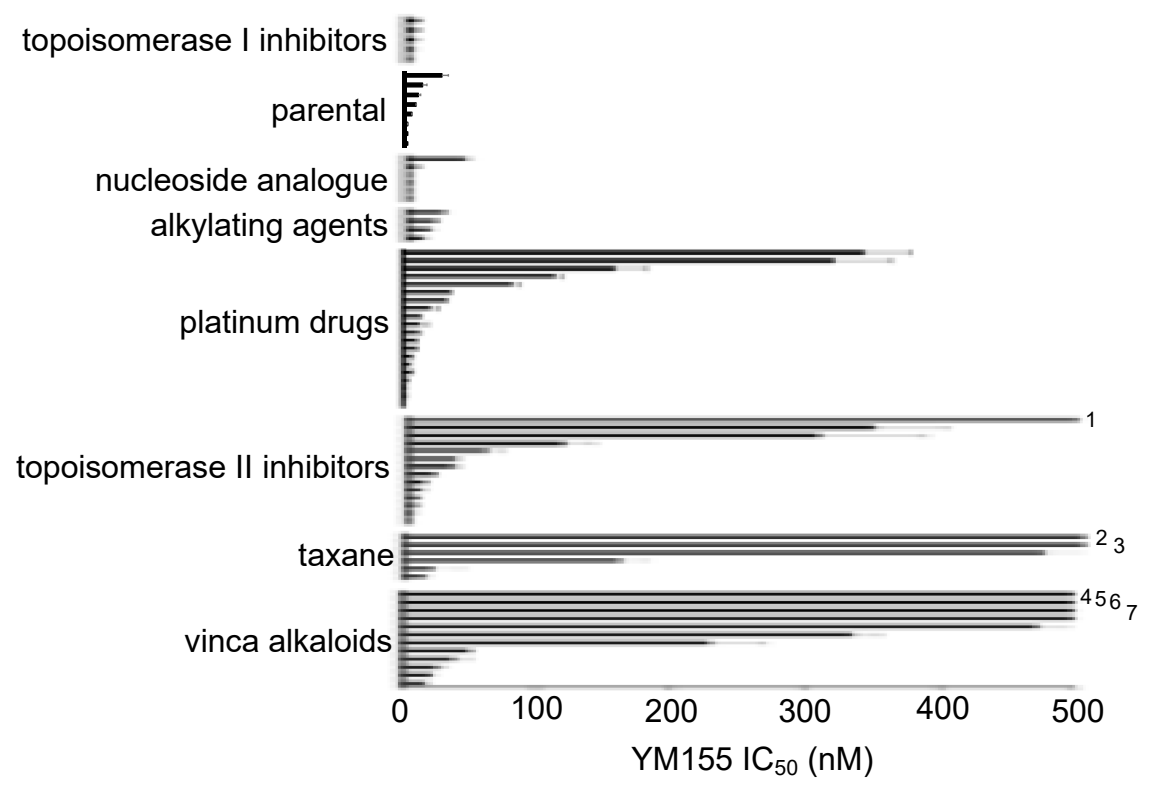

Figure 4. Effects of YM155 on the viability of neuroblastoma cell lines adapted to particular drug classes. Distribution of the YM155 IC50 values (mean \pm S.D., $n=3$ ) within the groups of drug-adapted cancer cell lines. Numerical data are presented in Table S1. ${ }^{1}$ UKF-NB-3rDOX ${ }^{20}$ (YM155 IC50 15,700 \pm 1,019 nM); ${ }^{2}$ MR-5rDOCE ${ }^{20}$ (YM155 IC50 21,549 \pm 638 nM); ${ }^{3}$ UKF-NB-2rDOX ${ }^{20}$ (YM155 IC50 1,108 \pm 179 $\mathrm{nM}) ;{ }^{4} \mathrm{NGPrVCR}^{20}$ (YM155 IC50 6,986 $\left.\pm 716 \mathrm{nM}\right) ;{ }^{5} \mathrm{UKF}-\mathrm{NB}-2^{\mathrm{r}} \mathrm{VCR}^{10}$ (YM155 IC50 5,940 $\left.\pm 247 \mathrm{nM}\right) ;{ }^{6} \mathrm{IMR}-$



The groups differed in the fraction of cell lines that displayed YM155 IC50 values $<56 \mathrm{nM}$. All of the eight parental, four alkylating agent-resistant, five topoisomerase I inhibitor-resistant, and six nucleoside analogue (gemcitabine)-resistant cell lines displayed YM155 IC 50 values $<56 \mathrm{nM}$. Only 15 out of $20(75 \%)$ platinum drug-adapted, nine out of $14(64 \%)$ topoisomerase II inhibitor-adapted, five out of $12(42 \%)$ vinca alkaloid-adapted, and two out of six (33\%) taxane (docetaxel)-adapted cell lines exhibited YM155 IC50 values $<56$ nM (Figure 4, Table S1).

For the topoisomerase II inhibitor (doxorubicin, etoposide)- and platinum drug (carboplatin, cisplatin, oxaliplatin)-adapted cell lines, we had sufficient data to perform drug-specific analyses. For six cell lines, we had doxorubicin- and etoposide-resistant sub-lines (Figure 5A, Figure 5B, Table S1). To determine the mean YM155 IC50 value, we again removed the UKF-NB-3 sub-lines because of the high value of UKF-NB-3rDOX ${ }^{20}$. Results revealed that acquired doxorubicin resistance resulted in a generally more pronounced YM155 resistance phenotype than acquired etoposide resistance (Figure 5A, Figure 5B, Table S1).

In addition, the project cell line panel included carboplatin-, cisplatin-, and oxaliplatin-resistant sub-lines of five neuroblastoma cell lines (Figure 5C, Figure 5D, Table S1). Cisplatin and oxaliplatin resistance were associated with a lower degree of YM155 resistance than carboplatin resistance (Figure 5C, Figure 5D, Table S1). 
A

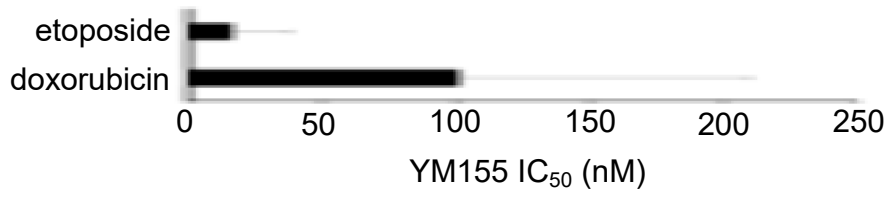

B
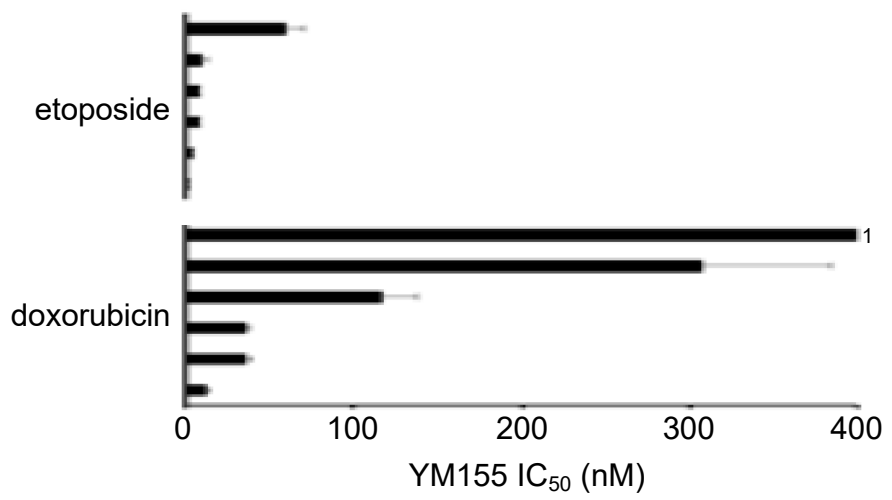

C



D



Figure 5. Effects of YM155 on the viability of neuroblastoma cell lines adapted to particular drugs. (A) YM155 concentrations that reduce the viability of neuroblastoma cell lines adapted to the topoisomerase II inhibitors doxorubicin or etoposide by $50 \%$ (IC50) as determined by MTT assay after a 5-day treatment period. Values are presented as mean \pm S.D. over all cell lines from the individual groups. The cell line UKF-NB-3rDOX ${ }^{20}$ was not included into this analysis because it was regarded as outliers (please refer to the text). (B) Distribution of the YM155 IC50 values (mean \pm S.D., $n=3$ ) in doxorubicin- and etoposide-adapted cells. (C) YM155 IC50 concentrations in neuroblastoma cell lines adapted to the platinum drugs carboplatin, cisplatin, or oxaliplatin (mean \pm S.D)) as determined by MTT assay after a 5-day treatment period. (D) Distribution of the YM155 IC50 values (mean \pm S.D., $n$ =3) in carboplatin-, cisplatin- and oxaliplatin-adapted cells. Numerical data are presented in Table S1 and Table S6. ${ }^{1}$ UKF-NB-3rDOX ${ }^{20}$ (YM155 IC50 15,700 $\pm 1,019$ nM).

\subsection{Role of ABCB1 in the YM155 response of Drug-Adapted Neuroblastoma Cells}

A significant amount of drug-adapted neuroblastoma cell lines displays increased ABCB1 activity [28], and $A B C B 1$ has been previously shown to mediate YM155 resistance $[6,10,19]$. In 
agreement with previous results, transduction of neuroblastoma cells with ABCB1 resulted in YM155 resistance, which was reduced by siRNA-mediated ABCB1 depletion (Figure 6, Figure S2). Further, YM155 $100 \mathrm{nM}$, a concentration that did not induce survivin depletion in ABCB1-transduced UKFNB-3 (UKF-NB-3АBCB1) cells after 24h of incubation, reduced cellular survivin levels in UKF-NB-3 ${ }^{\mathrm{ABCB} 1}$ cells in the presence of the ABCB1 inhibitors verapamil and zosuquidar (Figure 6, Figure S2).

A

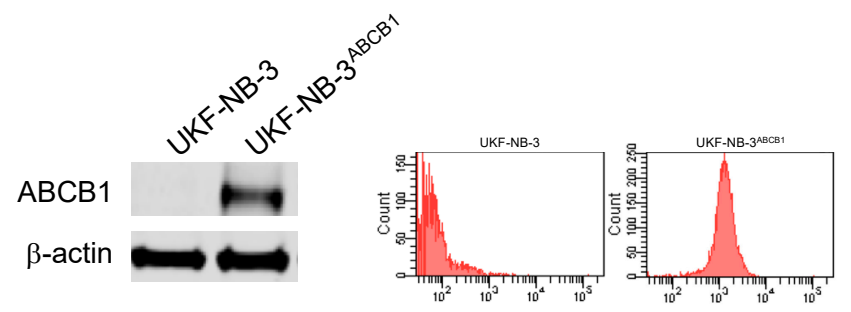

B

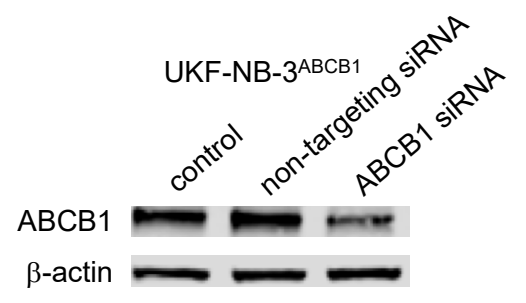

C

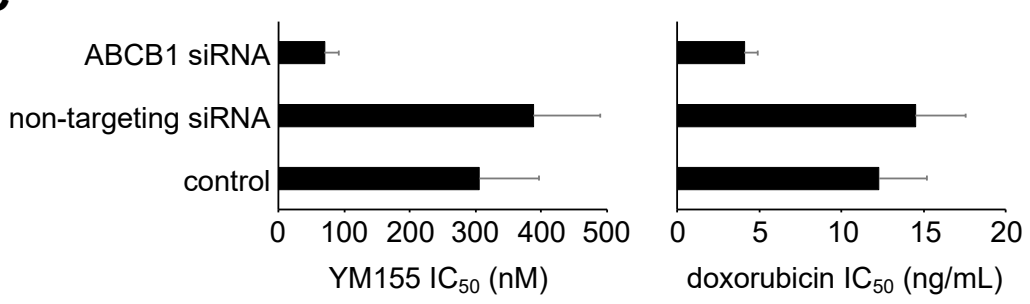

D

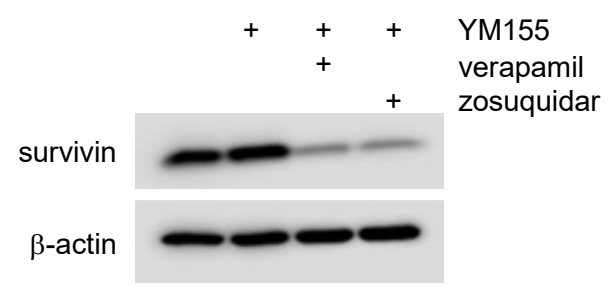

Figure 6. Effects of YM155 in ABCB1-transduced cells. (A) Representative western blots and flow cytometry histograms indicating ABCB1 levels in UKF-NB-3 cells and in UKF-NB-3 transduced with a lentiviral vector encoding $A B C B 1$ (UKF-NB-3 ${ }^{A B C B 1}$ ). (B) Effect of siRNA directed against ABCB1 on cellular ABCB1 levels in UKF-NB-3 $3^{A B C B 1}$ cells. (C) Concentrations of YM155 and doxorubicin (alternative ABCB1 substrate used as control) that reduce the viability of UKF-NB-3 ${ }^{\mathrm{ABCB} 1}$ cells by $50 \%$ (IC50, mean \pm S.D., $\mathrm{n}=3$ ) as determined by MTT assay after $120 \mathrm{~h}$ of incubation. (D) Effects of YM155 $(100 \mathrm{nM})$ on survivin levels in UKF-NB-3ABCB1 cells after $24 \mathrm{~h}$ of incubation in the presence or absence of verapamil $(5 \mu \mathrm{M})$ or zosuquidar $(1.25 \mu \mathrm{M})$. Uncropped Western blots are presented in Figure S2.

Hence, we further examined the effects of verapamil and zosuquidar on YM155 sensitivity in a panel of 60 drug-adapted neuroblastoma cell lines (Table S6). Fifteen of the drug-adapted cell lines displayed an IC 50 higher than $56 \mathrm{nM}$. In the presence of verapamil, only six of the drug-adapted cell lines displayed an $\mathrm{IC}_{50}$ higher $56 \mathrm{nM}$. In the presence of zosuquidar, only five of the drug-adapted cell lines displayed an $\mathrm{IC}_{50}$ higher than $56 \mathrm{nM}$. The YM155 IC 50 values of eight cell lines (IMR-5rDOX ${ }^{20}$, IMR-5rVCR ${ }^{10}$, IMRrVINB ${ }^{20}$, NGPrDOX ${ }^{20}$, NGPrETO ${ }^{400}$, UKF-NB-3rCARBO ${ }^{2000, ~ U K F-N B-3 r C D D P 1000, ~}$ 
UKF-NB-3rVINOR ${ }^{40}$ ) were reduced to levels below $56 \mathrm{nM}$ by verapamil and zosuquidar. Notably, the fold sensitisation by ABCB1 inhibitors was low (verapamil: 1.2-fold, zosuquidar: 1.5-fold) in NGPrETO400, although the YM155 IC50s were reduced below $56 \mathrm{nM}$. This suggests that ABCB1 expression is not a dominant YM155 resistance mechanism in NGPrETO400 cells (Table S6).

IMR-5rDOCE ${ }^{20}$, NGPrVCR ${ }^{20}$, and UKF-NB-2 ${ }^{\text {rCARBO }}{ }^{2000}$ were sensitised by verapamil and zosuquidar to YM155. However, the effects of zosuquidar were more pronounced resulting in YM155 IC 50 values below $56 \mathrm{nM}$, whereas the YM155 IC 50 values remained above $56 \mathrm{nM}$ in the presence of verapamil (Table S6). In NLFrDOX ${ }^{40}$ and NLFrVINB ${ }^{10}$ cells, zosuquidar (but not verapamil) increased the YM155 IC50 values by mechanisms that appear to be unrelated to ABCB1 (Table S6).

We selected two parental cell line/ drug-adapted subline pairs (IMR-5/IMR-5rDOCE20, IMR-32/ IMR-32rDOX ${ }^{20}$ ) for additional confirmatory experiments. The YM155 IC50s in these four cell lines in the absence and presence of zosuquidar determined MTT (used in the screen, measures oxidative phosphorylation in the mitochondria) were very similar to those determined by CellTiterGlo (alternative viability assay that measures ATP production) (Table S7). Both drug-adapted sublines displayed increased ABCB1 levels (Figure S3). Moreover, YM155 $500 \mathrm{nM}$, a concentration that did not affect cellular survivin levels and PARP cleavage in IMR-5rDOCE ${ }^{20}$ cells after $24 \mathrm{~h}$ incubation, caused survivin depletion and PARP cleavage in IMR $-5^{\mathrm{r} D O C E^{20}}$ cells in the presence of the ABCB1 inhibitors verapamil and zosuquidar (Figure 7, Figure S3).

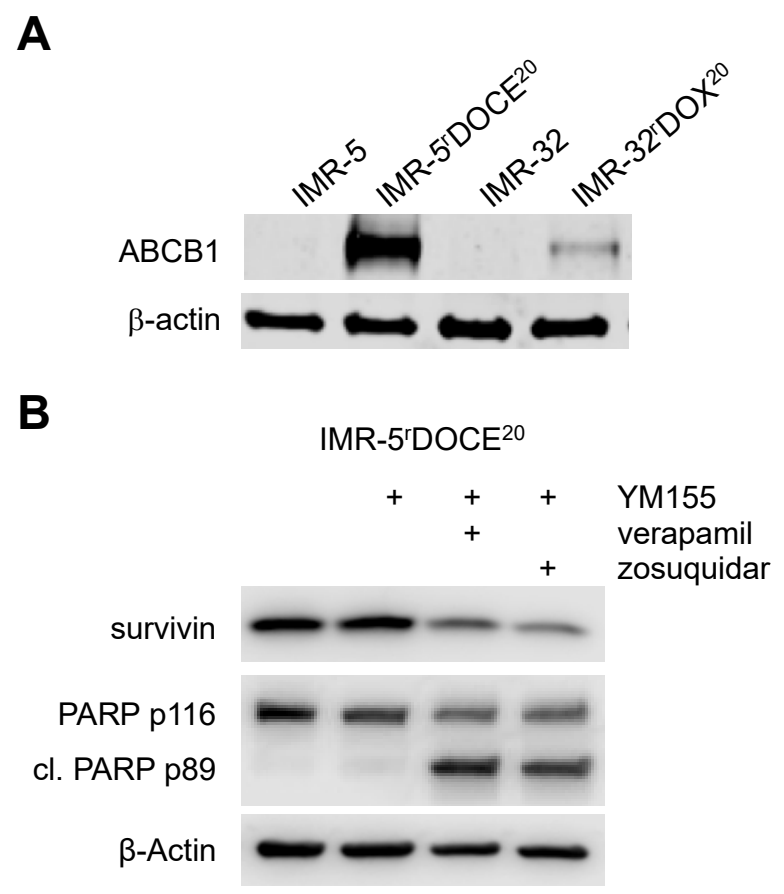

Figure 7. ABCB1 expression and YM155 activity in drug-adapted neuroblastoma cells. (A) Representative western blots indicating ABCB1 levels in IMR-5, IMR-5 ${ }^{\mathrm{r} D O C E^{20}}$, IMR-32, and IMR$32^{\mathrm{r} D O X^{20}}$. (B) Effects of YM155 (500 nM) on survivin levels and PARP cleavage in IMR-5 DOCE ${ }^{20}$ cells in the presence or absence of verapamil $(5 \mu \mathrm{M})$ or zosuquidar $(1.25 \mu \mathrm{M})$ after $24 \mathrm{~h}$ of incubation. Uncropped Western blots are presented in Figure S3.

\subsection{ABCC1 Mediates Resistance to YM155}

NLFrVCR ${ }^{10}$ cells were sensitised by verapamil but not by zosuquidar to YM155 (Table S6). $\mathrm{NLFrVCR}^{10}$ cells are characterised by ABCC1 (also known as MRP1) expression but do not express ABCB1 [29]. Since only verapamil but not zosuquidar inhibits ABCC1 [30,31], this suggests that ABCC1 also mediates resistance to YM155. In agreement, the ABCC1 inhibitor MK571 substantially reduced YM155 sensitivity in ABCC1-expressing NLFrVCR ${ }^{10}$ cells but not in the parental NLF cell line that does not express ABCC1 (Table S8). 


\subsection{Cross Resistance to YM155 is Caused by Multiple Resistance Mechanisms in Drug-Adapted Neuroblastoma Cells}

Although our data indicate that $\mathrm{ABCB} 1$ plays an important role in the cross-resistance of drugadapted neuroblastoma cell lines to YM155, additional mechanisms are also involved. Of the 60 drugadapted cell lines, 35 displayed cross-resistance to YM155 (fold change YM155 IC50 resistant sub-line/ YM155 IC50 respective parental cell line > 2). In 24 of these drug-adapted cell lines, the YM155 IC50 remained $>2$-fold higher in the presence of verapamil compared to the YM155 IC50 of the respective parental cell line in the presence of verapamil (Table S6). Similarly, in 19 drug-adapted cell lines, the YM155 IC 50 remained > 2-fold higher in the presence of zosuquidar compared to the YM155 IC50 of the respective parental cell line in the presence of zosuquidar (Table S6). This included cell lines that were not sensitised by verapamil and/ or zosuquidar to YM155 and those that were sensitised to YM155 by verapamil and/ or zosuquidar but not to the level of the parental cells (Table S6).

\subsection{Discrepancies in the Effects of the ABCB1 Inhibitors Verapamil and Zosuquidar on Neuroblastoma Cell Sensitivity to YM155}

Both, verapamil and zosuquidar, sensitised 25 of the drug-adapted cell lines to YM155 by >2fold. There was an overlap of 23 cell lines that were sensitised to YM155 by both ABCB1 inhibitors by $>2$-fold (Table S6). Among the exceptions was the ABCC1-expressing cell line NLFrVCR ${ }^{10}$ that has already been described above. NGPrGEMCI ${ }^{20}$ cells were sensitised to YM155 by zosuquidar, whereas verapamil slightly increased the YM155 IC 50 value in this cell line. In addition, UKF-NB-3rTOPO ${ }^{20}$ cells were sensitised to YM155 by verapamil by $>2$-fold (fold change 3.7 ) but not by zosuquidar (fold change 1.4). UKF-NB-6rCARBO2000 cells were sensitised by zosuquidar to YM155 by $>2$-fold (fold change 2.3) but not by verapamil (fold change 1.3) (Table S6). The reasons for these differences remain unclear.

Since we had detected differences between the effects of the ABCB1 inhibitors verapamil and zosuquidar on the YM155 IC50 values in a number of cell lines, we compared both drugs in a wider panel of 74 cell lines (Figure 8, Table S6). In 45 cell lines, the YM155 IC 50 values were in a similar range in the presence of verapamil and zosuquidar (YM155 IC 50 in the presence of verapamil/ YM155 IC 50 in the presence of zosuquidar $>0.5$ and $<2.0$ ). This included 33 cell lines that were neither sensitised to YM155 by verapamil nor by zosuquidar and 12 cell lines that were sensitised by verapamil and zosuquidar by more than 2 -fold and in a similar fashion (Table S6).

Thirteen cell lines were more strongly sensitised to YM155 by verapamil than by zosuquidar (YM155 IC50 in the presence of verapamil/YM155 IC 50 in the presence of zosuquidar $<0.5$ ). Only one of these cell lines (UKF-NB-6rETO ${ }^{200}$ ) was sensitised by both verapamil and zosuquidar to YM155 by more than 2-fold. The remaining cell lines were either only sensitised to YM155 by more than 2-fold by verapamil and not by zosuquidar, or zosuquidar increased the YM155 IC 50 by mechanisms that do not appear to be associated with effects on ABCB1 (Table S6).

Sixteen cell lines were more strongly sensitised to YM155 by zosuquidar than by verapamil (YM155 IC 50 in the presence of verapamil/ YM155 IC 50 in the presence of zosuquidar > 2.0). $\mathrm{NGPr}^{\mathrm{r} G E M C I^{20}}$ cells were only sensitised by zosuquidar to YM155 but not by verapamil. The other 15 of these cell lines were sensitised by more than 2-fold to YM155 by both compounds with zosuquidar exerting more pronounced effects. The relative differences between these two drugs on the YM155 sensitivity of these cell lines ranged from 2.2 (NLFrDOCE ${ }^{20}$, UKF-NB-3rCARBO ${ }^{2000}$ ) to 65.2 (UKF-NB3rDOCE ${ }^{10}$ ) (Table S6). 


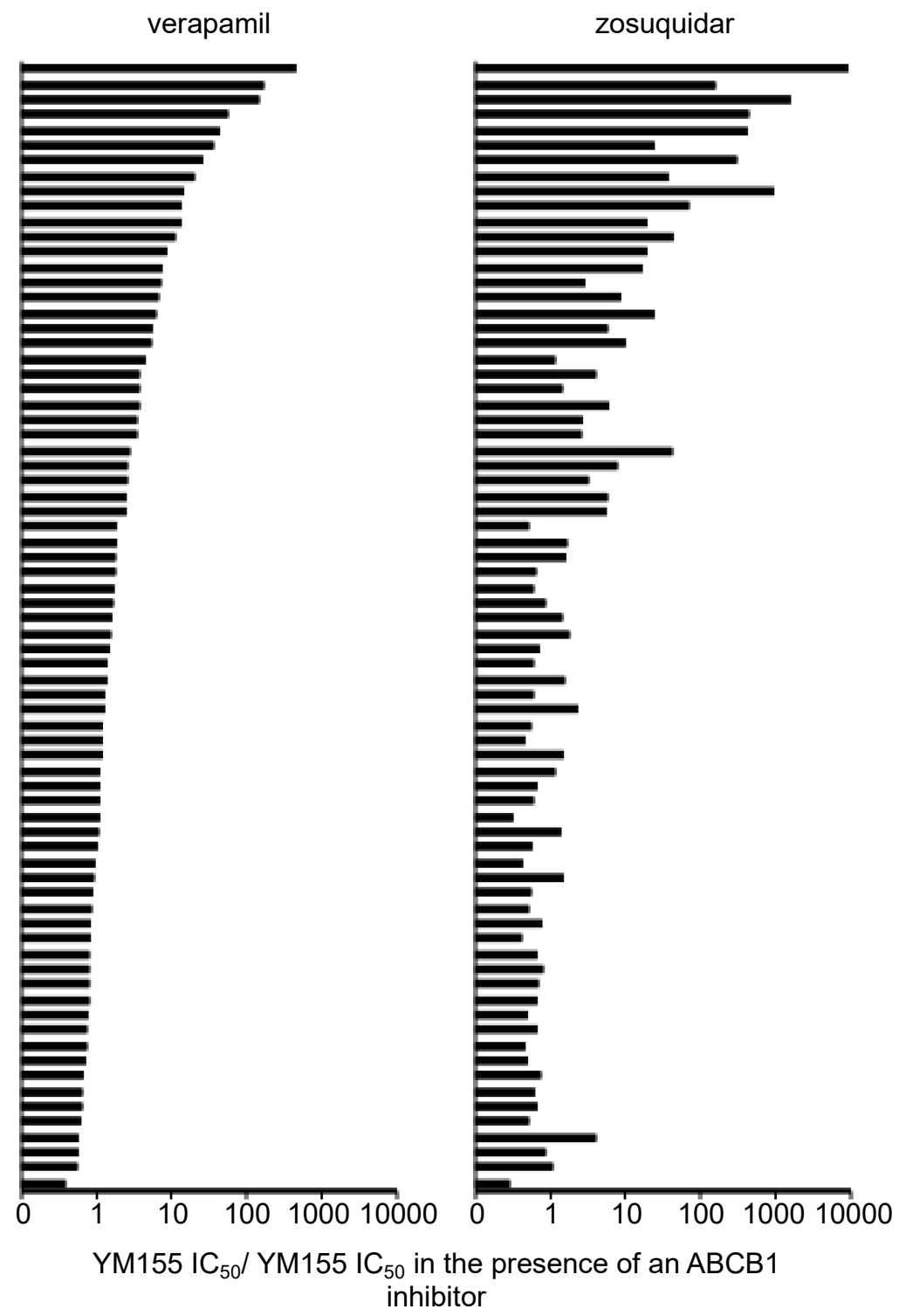

Figure 8. Comparison of verapamil- and zosuquidar-induced neuroblastoma cell sensitisation to YM155 in a panel of 74 neuroblastoma cell lines. The fold sensitisation (YM155 IC50/ YM155 IC50 in the presence of ABCB1 inhibitor) was determined by MTT assay after neuroblastoma cell incubation with YM155 for $120 \mathrm{~h}$ in the absence or presence of verapamil $(5 \mu \mathrm{M})$ or zosuquidar $(1.25 \mu \mathrm{M})$. Numerical data are presented in Table S6. ${ }^{1}$ UKF-NB-3rDOX ${ }^{20}$, fold change 9235; ${ }^{2}{ }^{2 M R}-{ }^{r}{ }^{r}{ }^{2} C^{20}$, fold change $1581 ;{ }^{3}$ UKF-NB-3rDOCE ${ }^{10}$, fold change 939.

\section{Discussion}

YM155 has been suggested as therapeutic option for the treatment of neuroblastoma including therapy-refractory disease $[6,7,10]$. In a larger cell line panel, mainly consisting of neuroblastoma cell lines with acquired drug resistance, we here show that 77 out of 101 tested neuroblastoma cell lines displayed YM155 IC50 values in the range of clinically achievable plasma concentrations up to $56 \mathrm{nM}$ [21-23].

Although MYCN amplification is a major indicator of poor prognosis in neuroblastoma [11,12], the efficacy of YM155 was independent of the MYCN status. As previously shown [6,10,19], ABCB1expressing cells displayed low YM155 sensitivity and were sensitised by the ABCB1 inhibitors verapamil and zosuquidar to YM155. The role of ABCB1 expression in neuroblastoma is not clear. 
ABCB1 expression at diagnosis is commonly regarded not to be of prognostic relevance [32], although $\mathrm{ABCB} 1$ expression has been reported in a significant fraction of patients $[6,33,34]$. Notably, six $(35 \%)$ out of the 17 parental neuroblastoma cell lines investigated in this study (Be(2)C, LAN-6, NB-S-124, SHEP, SK-N-AS, SK-N-SH) are characterised by ABCB1 activity, which is similar to a previous study, although there was some overlap between the cell line panels [6]. Limited information is available on ABCB1 expression as acquired drug resistance mechanism in neuroblastoma. Many drug-adapted neuroblastoma cell lines display enhanced ABCB1 activity [27,35], and drug-adapted cell lines have been shown to reflect clinically relevant resistance mechanisms [26,36-45]. Some clinical hints may also point towards a role of ABCB1 in acquired resistance in neuroblastoma [36,46]. Hence, ABCB1 may represent an acquired resistance mechanism in neuroblastoma.

In contrast to $\mathrm{ABCB} 1, \mathrm{ABCC} 1$ (also known as MRP1) is generally accepted as prognostic factor in neuroblastoma [23]. Interestingly, NLFrVCR ${ }^{10}$ cells (that express ABCC1 but not ABCB1 [29]) were sensitised to YM155 by verapamil (inhibits ABCB1 and ABCC1 [27]) but not by zosuquidar (inhibits only ABCB1 [31]). Moreover, the ABCC1 inhibitor MK571 sensitised NLFrVCR ${ }^{10}$ cells to YM155. This suggests that ABCC1 mediates YM155 resistance.

Verapamil and zosuquidar further differed in their effects on neuroblastoma cell sensitivity to YM155. Zosuquidar protected some ABCB1-negative cell lines from YM155-induced toxicity by unknown mechanisms. More strikingly, we identified cell line-specific differences in the relative potencies of verapamil and zosuquidar on YM155 activity. Twelve ABCB1-expressing cell lines were similarly sensitised to YM155 by verapamil and zosuquidar. Few cell lines were stronger sensitised by verapamil than by zosuquidar. These data are difficult to interpret with regard to ABCB1 because verapamil interacts with a broader range of transporters than the specific ABCB1 inhibitor zosuquidar [30,31,47]. However, 15 cell lines were sensitised by more than 2-fold to YM155 by verapamil and zosuquidar with zosuquidar exerting up to 65-fold (UKF-NB-3rDOCE ${ }^{10}$ ) more pronounced effects than verapamil. Hence, the relative effects of verapamil and zosuquidar on ABCB1-mediated YM155 transport differ in individual cell lines from similar efficacy (in 12 cell lines) to 65-fold increased zosuquidar efficacy over verapamil. Since zosuquidar is regarded as highly specific ABCB1 inhibitor [31,47], this difference seems to depend on discrepancies in the interaction with ABCB1. Notably, ABCB1 polymorphisms and mutations may substantially alter ABCB1 substrate specificity $[48,49]$, which may explain the cell line-specific variation in the relative influence of zosuquidar and verapamil on ABCB1 function. Hence, it might be possible to design ABCB1 inhibitors that preferentially target specific ABCB1 variants. In this context, we have previously shown that certain ABCB1 inhibitors preferentially interfere with the ABCB1-mediated transport of certain ABCB1 substrates [50].

Although RNAi-mediated p53 depletion decreases neuroblastoma cell sensitivity to YM155 as previously demonstrated [10], only 4 out of 14 nutlin-3-adapted TP53-mutant neuroblastoma cell lines displayed a >2-fold increased YM155 IC $_{50}$ relative to the respective parental cell line. All nutlin3-resistant cell lines remained sensitive to low nanomolar YM155 concentrations with IC50 values ranging from 0.40 to $1.50 \mathrm{nM}$. This shows that the role of p53 depends on the individual cellular context and that the TP53 status on its own does not indicate neuroblastoma cell sensitivity to YM155. These data are in accordance with initial findings that reported the activity of YM155 to be unrelated to the TP53 status $[13,51]$.

The adaptation of neuroblastoma cell lines to drugs from different classes was associated with varying YM155 sensitivity profiles. Neuroblastoma cell adaptation to topoisomerase I inhibitors, the nucleoside analogue gemcitabine, or alkylating agents was not associated with a pronounced YM155 resistance phenotype. In contrast, neuroblastoma cell lines adapted to the taxane docetaxel or vinca alkaloids exhibited distinct cross-resistance to YM155. Topoisomerase II inhibitors and platinum drugs displayed intermediate potential to induce YM155 resistance.

For the topoisomerase II inhibitor- and platinum drug-adapted neuroblastoma cell lines, we could perform drug-specific sub-analyses. Among the topoisomerase II inhibitors, doxorubicinresistant cells were more likely to be YM155-resistant than etoposide-resistant cells. This result may not be too surprising. Although doxorubicin and etoposide both inhibit the religation of the 
topoisomerase II cleavage complexes, they are structurally different compounds that differ in their exact interaction with this target and may exert additional varying effects [52-54]. Perhaps more strikingly, we also found differences among the carboplatin-, cisplatin-, and oxaliplatin-resistant cell lines. Carboplatin-resistant cells were more frequently YM155-resistant than cisplatin- or oxaliplatinresistant cells. This is surprising because platinum drugs share a similar mechanism of action. In particular, the effects of carboplatin and cisplatin are thought to be much more related to each other than to oxaliplatin $[55,56]$. The underlying reasons remain unclear, but the findings indicate substantial gaps in our understanding of the action of these frequently used drugs that need to be filled.

\section{Materials and Methods}

\subsection{Drugs}

YM155 (sepantronium bromide) and zosuquidar were purchased from Selleck Chemicals via BIOZOL Diagnostica GmbH (Eching, Germany), and verapamil was from Sigma-Aldrich (Munich, Germany).

\subsection{Cells}

The MYCN-amplified neuroblastoma cell lines UKF-NB-2, UKF-NB-3, UKF- and UKF-NB-6 were established from stage 4 neuroblastoma patients [26,57,58]. UKF-NB-3clone1 and UKF-NB3 clone3 are p53 wild-type single cell-derived sub-lines of UKF-NB-3 [26]. Be(2)C, IMR-32, SH-SY5Y, SK-N-AS, and SK-N-SH were obtained from ATCC (Manassas, VA, USA), CHP-134, LAN-6, NGP, and NMB from DMSZ (Braunschweig, Germany), and GI-ME-N from ICLC (Genova, Italy). IMR-5, NLF, and SHEP were kindly provided by Dr Angelika Eggert (Universität Duisburg-Essen, Germany). The MYCN-amplified NB-S-124 cell line was established by Dr Frank Westermann (DKFZ, Heidelberg, Germany). A master cell bank was established at the beginning of the project, and experiments on cell lines were performed within 20 passages.

Resistant neuroblastoma cell lines were established by continuous exposure to increasing drug concentrations as previously described [26] and derived from the Resistant Cancer Cell Line (RCCL) collection (www.kent.ac.uk/stms/cmp/RCCL/RCCLabout.html).

All cells were propagated in Iscove's modified Dulbecco's medium (IMDM) supplemented with $10 \%$ foetal calf serum (FCS), $100 \mathrm{IU} / \mathrm{ml}$ penicillin and $100 \mu \mathrm{g} / \mathrm{ml}$ streptomycin at $37^{\circ} \mathrm{C}$. Drug-adapted cell lines were continuously cultivated in the presence of the respective adaptation drugs but were released from the respective adaptation drugs before they were used for experiments. Cells were routinely tested for mycoplasma contamination and authenticated by short tandem repeat profiling.

p53-depleted and ABCB1-transduced neuroblastoma cells were established as described previously [26] using the Lentiviral Gene Ontology (LeGO) vector technology (www.lentigovectors.de). SH-EP-MYCN (TET21N) were cultured and induced as previously described [25].

\subsection{Viability Assay}

Cell viability was determined by the 3-(4,5-dimethylthiazol-2-yl)-2,5-diphenyltetrazolium bromide (MTT) dye reduction assay as described previously [26] or by CellTiterGlo assay (Promega, Walldorf, Germany) following the manufacturer's instructions after $120 \mathrm{~h}$ incubation.

\subsection{Western Blot}

Cells were lysed using Triton-X-100 sample buffer, and proteins were separated by SDS-PAGE. Detection occurred by using specific antibodies against $\beta$-actin (Biovision through BioCat $\mathrm{GmbH}$, Heidelberg Germany), ABCB1, poly (ADP-ribose) polymerase (PARP) (both from Cell Signaling via New England Biolabs, Frankfurt, Germany), MYCN (abcam, Cambridge, UK), and survivin (R\&D Systems, Minneapolis, MN, USA). Protein bands were visualised by laser-induced fluorescence using infrared scanner for protein quantification (Odyssey, Li-Cor Biosciences, Lincoln, NE, USA). 


\section{5. $R N A$ Interference (RNAi)}

Transient depletion of ABCB1 was achieved using synthetic siRNA oligonucleotides (ONTARGETplus SMARTpool) from Dharmacon (Lafayette, CO; USA). Non-targeting siRNA (ONTARGETplus SMARTpool) was used as negative control. Cells were transfected by electroporation using the NEON Transfection System (Invitrogen, Darmstadt; Germany) according to the manufacturer protocol. Cells were grown to $60-80 \%$ confluence, trypsinised, and $1.2 \times 10^{6}$ cells were re-suspended in $200 \mu \mathrm{l}$ resuspension buffer $\mathrm{R}$ including $2.5 \mu \mathrm{M}$ siRNA. The electroporation was performed using two 20 millisecond pulses of $1400 \mathrm{~V}$. Subsequently, the cells were transferred into cell culture plates or flasks, containing pre-warmed cell culture medium.

\subsection{TP53 Sequencing}

TP53 gene sequencing on cDNAs was performed using the following four pairs of primers: TP53 Ex2-3-f GTGACACGCTTCCCTGGAT and TP53 Ex2-3-r TCATCTGGACCTGGGTCTTC; TP53 Ex45-f CCCTTCCCAGAAAACCTACC and TP53 Ex4-5-r CTCCGTCATGTGCTGTGACT; TP53 EX6-7f GTGCAGCTGTGGGTTGATT and TP53 Ex6-7r GGTGGTACAGTCAGAGCCAAC; Tp53 Ex8-9-f CCTCACCATCATCACACTGG and TP53 Ex8-9-r GTCTGGTCCTGAAGGGTGAA. In addition, all cell lines were examined for TP53 mutations by sequence analysis of genomic DNA as described previously [26]. PCR was performed as described before [26]. Each amplicon was sequenced bidirectionally.

\subsection{Statistics}

Results are expressed as mean \pm S.D. of at least three experiments. Comparisons between two groups were performed using Student's t-test. Three or more groups were compared by ANOVA followed by the Student-Newman-Keuls test. P values lower than 0.05 were considered to be significant.

\section{Conclusions}

The investigation of YM155 in 101 neuroblastoma cell lines revealed complex sensitivity profiles and that larger panels of model systems are needed to uncover this complexity. Our findings confirm 1) that YM155 is a drug candidate for neuroblastoma including therapy-refractory disease with the majority of cell lines being sensitive to clinically achievable YM155 concentrations and 2) that ABCB1 is an important determinant of YM155 sensitivity. Notably, there were substantial differences in the relative efficacy of the ABCB1 inhibitors verapamil and zosuquidar in sensitising ABCB1-expressing cells to YM155. These differences may be caused by sequence variations in the transporters in the different cell lines, which suggests that it may be possible to design variant-specific ABCB1 inhibitors. Moreover, we present novel findings indicating 1) that YM155 resistance is also mediated by ABCC1 (an ABC transporter of prognostic relevance in neuroblastoma [32]), 2) that (in contrast to previous assumptions) the p53 status does not indicate YM155 sensitivity, and 3) that YM155 cross-resistance profiles differ between cell lines adapted to drugs from different classes and even between cell lines adapted to drugs as similar as cisplatin and carboplatin. YM155 has shown moderate effects in clinical trials so far $[23,59,60]$. An improved understanding of the complex processes underlying response to this drug may enable the identification of biomarkers and the design more effective personalised therapies.

Supplementary Materials: The following are available online at www.mdpi.com/xxx/s1, Figure S1: Effects of MYCN expression on neuroblastoma cell sensitivity to YM155, Figure S2: Effects of YM155 in ABCB1-transduced cells, Figure S3: ABCB1 expression and YM155 activity in drug-adapted neuroblastoma cells, Table S1: YM155 concentrations that reduce the viability of neuroblastoma cell lines by 50\% (IC50), Table S2: ABCB1 phenotype of cell lines, Table S3: YM155 concentrations that reduce the viability of MYCN-amplified and non-MYCNamplified neuroblastoma cell lines by 50\% (IC50), Table S4: YM155 concentrations that reduce the viability of neuroblastoma cell lines with varying p53 status by 50\% (IC50), Table S5: Mean YM155 concentrations that reduce the viability of neuroblastoma cell lines with resistance to certain drug classes by 50\% (IC50), Table S6: YM155 
concentrations that reduce the viability of neuroblastoma cell lines by $50 \%$ (IC50) in the absence or presence of the ABCB1 inhibitors verapamil $(5 \mu \mathrm{M})$ or zosuquidar $(1.25 \mu \mathrm{M})$, Table S7: YM155 concentrations that reduce the viability of neuroblastoma cell lines by $50 \%$ (IC50) in the absence or presence of zosuquidar $(1.25 \mu \mathrm{M})$ as indicated by MTT assay or CellTiterGlo after 120h of incubation, Table S8: YM155 concentrations that reduce the viability of neuroblastoma cell lines by $50 \%$ (IC50) in the absence or presence of the ABCC1 inhibitor MK571 (10 $\mu \mathrm{M})$.

Author Contributions: Conceptualization, M.M. and J.C.jr.; Methodology, all authors; Formal Analysis, all authors; Investigation, all authors; Resources, A.v.D., F.W., Fr.R. and J.C.jr.; Data Curation, M.M., A.v.D., Fr.R. and J.C.jr.; Writing-Original Draft Preparation, M.M. and J.C.jr.; Writing Review \& Editing - all authors; Supervision, M.M., A.v.D., Fr.R. and J.C.jr.; Project Administration, M.M. and J.C.jr.; Funding Acquisition, J.C.jr. All authors have read and agreed to the published version of the manuscript

Funding: This research was funded by the Hilfe für krebskranke Kinder Frankfurt e.V. and the Frankfurter Stiftung für krebskranke Kinder. The APC was funded by institutional membership of the Goethe-University.

Acknowledgments: The authors thank Kristoffer Riecken and Boris Fehse (Universitätsklinikum HamburgEppendorf) for provision and support with the LeGO vectors..

Conflicts of Interest: The authors declare no conflict of interest. The funders had no role in the design of the study; in the collection, analyses, or interpretation of data; in the writing of the manuscript, or in the decision to publish the results.

\section{References}

1. Rödel, F.; Sprenger, T.; Kaina, B.; Liersch, T.; Rödel, C.; Fulda, S.; Hehlgans, S. Survivin as a Prognostic/Predictive Marker and Molecular Target in Cancer Therapy. Curr. Med. Chem. 2012, 19, 36793688, doi:10.2174/092986712801661040.

2. Li, F.; Aljahdali, I.; Ling, X. Cancer therapeutics using survivin BIRC5 as a target: what can we do after over two decades of study? J. Exp. Clin. Cancer Res. 2019, 38, 368, doi:10.1186/s13046-019-1362-1.

3. Wheatley, S.P.; Altieri, D.C. Survivin at a glance. J. Cell. Sci. 2019, 132, doi:10.1242/jcs.223826.

4. Goldsmith, K.C.; Hogarty, M.D. Targeting programmed cell death pathways with experimental therapeutics: opportunities in high-risk neuroblastoma. Cancer Lett. 2005, 228, 133-41, doi:10.1016/j.canlet.2005.01.048.

5. Lamers, F.; van der Ploeg, I.; Schild, L.; Ebus, M.E.; Koster, J.; Hansen, B.R.; Koch, T.; Versteeg, R.; Caron, H.N.; Molenaar, J.J. Knockdown of survivin (BIRC5) causes apoptosis in neuroblastoma via mitotic catastrophe. Endocr. Relat. Cancer 2011, 18, 657-668, doi:10.1530/ERC-11-0207.

6. Lamers, F.; Schild, L.; Koster, J.; Versteeg, R.; Caron, H.N.; Molenaar, J.J. Targeted BIRC5 silencing using YM155 causes cell death in neuroblastoma cells with low ABCB1 expression. Eur. J. Cancer 2012, 48, $763-$ 771, doi:10.1016/j.ejca.2011.10.012.

7. Liang, H.; Zhang, L.; Xu, R.; Ju, X.L. Silencing of survivin using YM155 induces apoptosis and chemosensitization in neuroblastomas cells. Eur. Rev. Med. Pharmacol. Sci. 2013, 17, 2909--2915.

8. Rauch, A.; Hennig, D.; Schäfer, C.; Wirth, M.; Marx, C.; Heinzel, T.; Schneider, G.; Krämer, O.H. Survivin and YM155: how faithful is the liaison? Biochim. Biophys. Acta. 2014, 1845, 202-220, doi:10.1016/j.bbcan.2014.01.003.

9. Hagenbuchner, J.; Kiechl-Kohlendorfer, U.; Obexer, P.; Ausserlechner, M.J. BIRC5/Survivin as a target for glycolysis inhibition in high-stage neuroblastoma. Oncogene 2016, 35, 2052-2061, doi:10.1038/onc.2015.264.

10. Voges, Y.; Michaelis, M.; Rothweiler, F.; Schaller, T.; Schneider, C.; Politt, K.; Mernberger, M.; Nist, A.; Stiewe, T.; Wass, M.N.; et al. Cell Death Dis. 2016, 7, e2410. doi:10.1038/cddis.2016.257.

11. Morgenstern, D.A.; Baruchel, S.; Irwin, M.S. Current and future strategies for relapsed neuroblastoma: challenges on the road to precision therapy. J. Pediatr. Hematol. Oncol. 2013, 35, 337-347, doi:10.1097/MPH.0b013e318299d637

12. Park, J.R.; Bagatell, R.; London, W.B.; Maris, J.M.; Cohn, S.L.; Mattay, K.K.; Hogarty, M.; COG Neuroblastoma Committee. Children's Oncology Group's 2013 blueprint for research: neuroblastoma. Pediatr. Blood Cancer 2013, 60, 985-993, doi:10.1002/pbc.24433.

13. Nakahara, T.; Kita, A.; Yamanaka, K.; Mori, M.; Amino, N.; Takeuchi, M.; Tominaga, F.; Hatakeyama, S.; Kinoyama, I.; Matsuhisa, A.; et al. YM155, a novel small-molecule survivin suppressant, induces regression 
of established human hormone-refractory prostate tumor xenografts. Cancer Res. 2007, 67, 8014-8011, doi:10.1158/0008-5472.CAN-07-1343.

14. Glaros, T.G.; Stockwin, L.H.; Mullendore, M.E.; Smith, B.; Morrison, B.L.; Newton, D.L. The "survivin suppressants" NSC 80467 and YM155 induce a DNA damage response. Cancer Chemother. Pharmacol. 2012, 70, 207-212, doi:10.1007/s00280-012-1868-0.

15. Chang, B.H.; Johnson, K.; LaTocha, D.; Rowley, J.S.; Bryant, J.; Burke, R.; Smith, R.L.; Loriaux, M.; Müschen, M.; Mullighan, C.; et al. YM155 potently kills acute lymphoblastic leukemia cells through activation of the DNA damage pathway. J. Hematol. Oncol. 2015, 8, 39, doi:10.1186/s13045-015-0132-6.

16. Tang, H.; Shao, H.; Yu, C.; Hou, J. Mcl-1 downregulation by YM155 contributes to its synergistic anti-tumor activities with ABT-263. Biochem. Pharmacol. 2011, 82, 1066-1072, doi:10.1016/j.bcp.2011.07.064.

17. Wagner, V.; Hose, D.; Seckinger, A.; Weiz, L.; Meißner, T.; Rème, T.; Breitkreutz, I.; Podar, K.; Ho, A.D.; Goldschmidt, H.; et al. Preclinical efficacy of sepantronium bromide (YM155) in multiple myeloma is conferred by down regulation of Mcl-1. Oncotarget 2014, 5, 10237-10250, doi:10.18632/oncotarget.2529.

18. de Necochea-Campion, R.; Diaz Osterman, C.J.; Hsu, H.W.; Fan, J.; Mirshahidi, S.; Wall, N.R.; Chen, C.S. AML sensitivity to YM155 is modulated through AKT and Mcl-1. Cancer Lett. 2015, 366, 44-51, doi:10.1016/j.canlet.2015.05.034.

19. Iwai, M.; Minematsu, T.; Li, Q.; Iwatsubo, T.; Usui, T. Utility of P-glycoprotein and organic cation transporter 1 double-transfected LLC-PK1 cells for studying the interaction of YM155 monobromide, novel small-molecule survivin suppressant, with P-glycoprotein. Drug Metab. Dispos. 2011, 39, 2314-2320, doi:10.1124/dmd.111.040733.

20. Winter, G.E.; Radic, B.; Mayor-Ruiz, C.; Blomen, V.A.; Trefzer, C.; Kandasamy, R.K.; Huber, K.V.M.; Gridling, M.; Chen, D.; Klampfl, T.; et al. The solute carrier SLC35F2 enables YM155-mediated DNA damage toxicity. Nat. Chem. Biol. 2014, 10, 768-773, doi:10.1038/nchembio.1590.

21. Tolcher, A.W.; Mita, A.; Lewis, L.D.; Garrett, C.R.; Till, E.; Daud, A.I.; Patnaik, A.; Papadopoulos, K.; Takimoto, C.; Bartels, P.; et al. Phase I and pharmacokinetic study of YM155, a small-molecule inhibitor of survivin. J. Clin. Oncol. 2008, 26, 5198-5203, doi:10.1200/JCO.2008.17.2064.

22. Satoh, T.; Okamoto, I.; Miyazaki, M.; Morinaga, R.; Tsuya, A.; Hasegawa, Y.; Terashima, M.; Ueda, S.; Fukuoka, M.; Ariyoshi, Y.; et al. Phase I study of YM155, a novel survivin suppressant, in patients with advanced solid tumors. Clin. Cancer Res. 2009, 15, 3872-3880, doi:10.1158/1078-0432.CCR-08-1946.

23. Aoyama, Y.; Kaibara, A.; Takada, A.; Nishimura, T.; Katashima, M.; Sawamoto, T. Population pharmacokinetic modeling of sepantronium bromide (YM155), a small molecule survivin suppressant, in patients with non-small cell lung cancer, hormone refractory prostate cancer, or unresectable stage III or IV melanoma. Invest. New Drugs 2013, 31, 443-451, doi:10.1007/s10637-012-9867-x.

24. McDevitt, C.A.; Callaghan, R. How can we best use structural information on P-glycoprotein to design inhibitors? Pharmacol. Ther. 2007, 113, 429-441, doi:10.1016/j.pharmthera.2006.10.003

25. Lutz, W.; Stöhr, M.; Schürmann, J.; Wenzel, A.; Löhr, A.; Schwab, M. Conditional expression of N-myc in human neuroblastoma cells increases expression of alpha-prothymosin and ornithine decarboxylase and accelerates progression into S-phase early after mitogenic stimulation of quiescent cells. Oncogene 1996, 13, 803-812.

26. Michaelis, M.; Rothweiler, F.; Barth, S.; Cinatl, J.; van Rikxoort, M.; Löschmann, N.; Voges, Y.; Breitling, R.; von Deimling, A.; Rödel, F.; et al. Adaptation of cancer cells from different entities to the MDM2 inhibitor nutlin-3 results in the emergence of p53-mutated multi-drug-resistant cancer cells. Cell Death Dis. 2011, 2, e243, doi:10.1038/cddis.2011.129.

27. Michaelis, M.; Rothweiler, F.; Agha, B.; Barth, S.; Voges, Y.; Löschmann, N.; von Deimling, A.; Breitling, R.; Doerr, H.W.; Rödel, F.; et al. Human neuroblastoma cells with acquired resistance to the p53 activator RITA retain functional p53 and sensitivity to other p53 activating agents. Cell Death Dis. 2012, 3, e294, doi:10.1038/cddis.2012.35.

28. Löschmann, N.; Michaelis, M.; Rothweiler, F.; Zehner, R.; Cinatl, J.; Voges, Y.; Sharifi, M.; Riecken, K.; Meyer, J.; von Deimling, A.; et al. Testing of SNS-032 in a panel of human neuroblastoma cell lines with acquired resistance to a broad range of drugs. Transl. Oncol. 2013, 6, 685-696, doi:10.1593/tlo.13544.

29. Löschmann, N.; Michaelis, M.; Rothweiler, F.; Voges, Y.; Balónová, B.; Blight, B.A.; Cinatl, J. Jr. ABCB1 as predominant resistance mechanism in cells with acquired SNS-032 resistance. Oncotarget 2016, 7, 5805158064, doi:10.18632/oncotarget.11160. 
30. Abe, T.; Koike, K.; Ohga, T.; Kubo, T.; Wada, M.; Kohno, K.; Mori, T.; Hidaka, K.; Kuwano, M. Chemosensitisation of spontaneous multidrug resistance by a 1,4-dihydropyridine analogue and verapamil in human glioma cell lines overexpressing MRP or MDR1. Br. J. Cancer 1995, 72, 418-423, doi:10.1038/bjc.1995.348.

31. Dantzig, A.H.; Shepard, R.L.; Law, K.L.; Tabas, L.; Pratt, S.; Gillespie, J.S.; Binkley, S.N.; Kuhfeld, M.T.; Starling, J.J.; Wrighton, S.A. Selectivity of the multidrug resistance modulator, LY335979, for P-glycoprotein and effect on cytochrome P-450 activities. J. Pharmacol. Exp. Ther. 1999, 290, 854-862.

32. Yu, D.M.; Huynh, T.; Truong, A.M.; Haber, M.; Norris, M.D. ABC transporters and neuroblastoma. Adv. Cancer Res. 2015, 125, 139-170, doi:10.1016/bs.acr.2014.10.005.

33. Pituch-Noworolska, A.; Zaremba, M.; Wieczorek, A. Expression of proteins associated with therapy resistance in rhabdomyosarcoma and neuroblastoma tumour cells. Pol. J. Pathol. 2009, 60, 168-173.

34. Oue, T.; Yoneda, A.; Uehara, S.; Yamanaka, H.; Fukuzawa, M. Increased expression of multidrug resistanceassociated genes after chemotherapy in pediatric solid malignancies. J. Pediatr. Surg. 2009, 44, 377-380, doi:10.1016/j.jpedsurg.2008.10.088.

35. Michaelis, M.; Rothweiler, F.; Löschmann, N.; Sharifi, M.; Ghafourian, T.; Cinatl, J. Jr. Enzastaurin inhibits ABCB1-mediated drug efflux independently of effects on protein kinase C signalling and the cellular p53 status. Oncotarget 2015, 6, 17605-17620, doi:10.18632/oncotarget.2889.

36. Engelman, J.A.; Zejnullahu, K.; Mitsudomi, T.; Song, Y.; Hyland, C.; Park, J.O.; Lindeman, N.; Gale, C.M.; Zhao, X.; Christensen, J.; et al. MET amplification leads to gefitinib resistance in lung cancer by activating ERBB3 signaling. Science 2007, 316, 1039-1043, doi:10.1126/science.1141478.

37. Nazarian, R.; Shi, H.; Wang, Q.; Kong, X.; Koya, R.C.; Lee, H.; Chen, Z.; Lee, M.K.; Attar, N.; Sazegar, H.; et al. Melanomas acquire resistance to B-RAF(V600E) inhibition by RTK or N-RAS upregulation. Nature 2010, 468, 973-977, doi:10.1038/nature09626.

38. Poulikakos, P.I.; Persaud, Y.; Janakiraman, M.; Kong, X.; Ng, C.; Moriceau, G.; Shi, H.; Atefi, M.; Titz, B.; Gabay, M.T.; et al. RAF inhibitor resistance is mediated by dimerization of aberrantly spliced BRAF(V600E). Nature 2011, 480, 387-390, doi:10.1038/nature10662.

39. Domingo-Domenech, J.; Vidal, S.J.; Rodriguez-Bravo, V.; Castillo-Martin, M.; Quinn, S.A.; RodriguezBarrueco, R.; Bonal, D.M.; Charytonowicz, E.; Gladoun, N.; de la Iglesia-Vicente, J.; et al. Suppression of acquired docetaxel resistance in prostate cancer through depletion of notch- and hedgehog-dependent tumor-initiating cells. Cancer Cell 2012, 22, 373-388, doi:10.1016/j.ccr.2012.07.016.

40. Joseph, J.D.; Lu, N.; Qian, J.; Sensintaffar, J.; Shao, G.; Brigham, D.; Moon, M.; Maneval, E.C.; Chen, I.; Darimont, B.; et al. A clinically relevant androgen receptor mutation confers resistance to secondgeneration antiandrogens enzalutamide and ARN-509. Cancer Discov. 2013, 3, 1020-1029, doi:10.1158/21598290.CD-13-0226.

41. Korpal, M.; Korn, J.M.; Gao, X.; Rakiec, D.P.; Ruddy, D.A.; Doshi, S.; Yuan, J.; Kovats, S.G.; Kim, S.; Cooke, V.G.; et al. An F876L mutation in androgen receptor confers genetic and phenotypic resistance to MDV3100 (enzalutamide). Cancer Discov. 2013, 3, 1030-1043, doi:10.1158/2159-8290.CD-13-0142.

42. Crystal, A.S.; Shaw, A.T.; Sequist, L.V.; Friboulet, L.; Niederst, M.J.; Lockerman, E.L.; Frias, R.L.; Gainor, J.F.; Amzallag, A.; Greninger, P.; et al. Patient-derived models of acquired resistance can identify effective drug combinations for cancer. Science 2014, 346, 1480-1486, doi:10.1126/science.1254721.

43. Niederst, M.J.; Sequist, L.V.; Poirier, J.T.; Mermel, C.H.; Lockerman, E.L.; Garcia, A.R.; Katayama, R.; Costa, C.; Ross, K.N.; Moran, T.; et al. RB loss in resistant EGFR mutant lung adenocarcinomas that transform to small-cell lung cancer. Nat. Commun. 2015, 6, 6377, doi:10.1038/ncomms7377.

44. Jung, J.; Lee, J.S.; Dickson, M.A.; Schwartz, G.K.; Le Cesne, A.; Varga, A.; Bahleda, R.; Wagner, A.J.; Choy, E.; de Jonge, M.J.; et al. TP53 mutations emerge with HDM2 inhibitor SAR405838 treatment in dedifferentiated liposarcoma. Nat. Commun. 2016, 7, 12609, doi:10.1038/ncomms12609.

45. Schneider, C.; Oellerich, T.; Baldauf, H.M.; Schwarz, S.M.; Thomas, D.; Flick, R.; Bohnenberger, H.; Kaderali, L.; Stegmann, L.; Cremer, A.; et al. SAMHD1 is a biomarker for cytarabine response and a therapeutic target in acute myeloid leukemia. Nat. Med. 2017, 23, 250-255, doi:10.1038/nm.4255.

46. Dhooge, C.R.; De Moerloose, B.M.; Benoit, Y.C.; Van Roy, N.; Philippé; Laureys, G.G. Expression of the MDR1 gene product P-glycoprotein in childhood neuroblastoma. Cancer 1997, 80, 1250-1257.

47. Palmeira, A.; Sousa, E.; Vasconcelos, M.H.; Pinto, M.M. Three decades of P-gp inhibitors: skimming through several generations and scaffolds. Curr. Med. Chem. 2012, 19, 1946-2025. doi:10.2174/092986712800167392. 
48. Sissung, T.M.; Baum, C.E.; Kirkland, C.T.; Gao, R.; Gardner, E.R.; Figg, W.D. Pharmacogenetics of membrane transporters: an update on current approaches. Mol. Biotechnol. 2010, 44, 152-167, doi:10.1007/s12033-009-9220-6.

49. Ieiri, I. Functional significance of genetic polymorphisms in P-glycoprotein (MDR1, ABCB1) and breast cancer resistance protein (BCRP, ABCG2). Drug Metab. Pharmacokinet. 2012, 27, 85-105, doi:10.2133/dmpk.dmpk-11-rv-098.

50. Michaelis, M.; Rothweiler, F.; Wurglics, M.; Aniceto, N.; Dittrich, M.; Zettl, H.; Wiese, M.; Wass, M.N.; Ghafourian, T.; Schubert-Zsilavecz, M.; et al. Substrate-specific effects of pirinixic acid derivatives on ABCB1-mediated drug transport. Oncotarget 2016, 7, 11664-11676, doi:10.18632/oncotarget.7345.

51. Nakahara, T.; Kita, A.; Yamanaka, K.; Mori, M.; Amino, N.; Takeuchi, M.; Tominaga, F.; Kinoyama, I.; Matsuhisa, A.; Kudou, M.; et al. Broad spectrum and potent antitumor activities of YM155, a novel smallmolecule survivin suppressant, in a wide variety of human cancer cell lines and xenograft models. Cancer Sci. 2011, 102, 614-621, doi:10.1111/j.1349-7006.2010.01834.x.

52. Pommier, Y.; Leo, E.; Zhang, H.; Marchand, C. DNA topoisomerases and their poisoning by anticancer and antibacterial drugs. Chem. Biol. 2010, 17, 421-433, doi:10.1016/j.chembiol.2010.04.012.

53. Meresse, P.; Dechaux, E.; Monneret, C.; Bertounesque, E. Etoposide: discovery and medicinal chemistry. Curr. Med. Chem. 2004, 11, 2443-2466, doi:10.2174/0929867043364531.

54. Broxterman, H.J.; Gotink, K.J.; Verheul, H.M. Understanding the causes of multidrug resistance in cancer: a comparison of doxorubicin and sunitinib. Drug Resist. Updat. 2009, 12, 114-126, doi:10.1016/j.drup.2009.07.001.

55. Kelland, L. The resurgence of platinum-based cancer chemotherapy. Nat. Rev. Cancer 2007, 7, 573-584, doi:10.1038/nrc2167.

56. Dilruba, S.; Kalayda, G.V. Platinum-based drugs: past, present and future. Cancer Chemother. Pharmacol. 2016, 77, 1103-1124, doi:10.1007/s00280-016-2976-z.

57. Kotchetkov, R.; Cinatl, J.; Blaheta, R.; Vogel, J.U.; Karaskova, J.; Squire, J.; Hernáiz Driever, P.; Klingebiel, T.; Cinatl, J. Jr. Development of resistance to vincristine and doxorubicin in neuroblastoma alters malignant properties and induces additional karyotype changes: a preclinical model. Int. J. Cancer 2003, 104, 36-43, doi:10.1002/ijc.10917.

58. Kotchetkov, R.; Driever, P.H.; Cinatl, J.; Michaelis, M.; Karaskova, J.; Blaheta, R.; Squire, J.A.; Von Deimling, A.; Moog, J.; Cinatl, J. Jr. Increased malignant behavior in neuroblastoma cells with acquired multi-drug resistance does not depend on P-gp expression. Int. J. Oncol. 2005, 27, 1029-1037.

59. Giaccone, G.; Zatloukal, P.; Roubec, J.; Floor, K.; Musil, J.; Kuta, M.; van Klaveren, R.J.; Chaudhary, S.; Gunther, A.; Shamsili, S. Multicenter phase II trial of YM155, a small-molecule suppressor of survivin, in patients with advanced, refractory, non-small-cell lung cancer. J. Clin. Oncol. 2009, 27, 4481-4486, doi:10.1200/JCO.2008.21.1862.

60. Tolcher, A.W.; Quinn, D.I.; Ferrari, A.; Ahmann, F.; Giaccone, G.; Drake, T.; Keating, A.; de Bono, J.S. A phase II study of YM155, a novel small-molecule suppressor of survivin, in castration-resistant taxanepretreated prostate cancer. Ann. Oncol. 2012, 23, 968-973, doi:10.1093/annonc/mdr353.

(C) 2020 by the authors. Licensee MDPI, Basel, Switzerland. This article is an open access article distributed under the terms and conditions of the Creative Commons Attribution (CC BY) license (http://creativecommons.org/licenses/by/4.0/). 